\title{
The epidemiological profile of knee injury pattern among different divisional football players
}

\author{
Atiqur Rahman Khan ${ }^{1}$, (D) Mohammad Jobair Khan ${ }^{2}$, \\ Mohammad Delwer Hossain Hawlader ${ }^{3}$ \\ ${ }^{1}$ Integrated Disability Service Center, JPUF, Ministry of Social Welfare, Madhobpur, Hobigonj, Bangladesh. \\ ${ }^{2}$ Department of Physiotherapy, Apollo Hospitals Dhaka, Dhaka, Bangladesh. \\ ${ }^{3}$ Department of Public Health, North South University, Dhaka, Bangladesh.
}

\begin{abstract}
Complete scenario of number and factors of knee injuries among the male footballers is intangible; therefore, it would seem essential to compute the injuries in relation to field condition and to show the nature and type of injuries including the possible risk factors. In a total of 200 of 215 soccer athletes playing at least one year professionally were randomized with the age range 14 - 40 years recruited from different divisional clubs. All information collected through questionnaires from five football clubs who were participating in the tournament from March 2011 to February 2012. In total, from 200 players, 116 of them suffered soft tissue injuries (29 per 100 players) in the knee on average 27 years of age. A higher percentage of injury explored in midfielder $35.5 \%$, and the ligament was the most common $63.8 \%$ soft tissue injury. 59\% participant noted about lack of a particular exercise regimen for the knee. Poor ground condition significantly associated with the injury $(x 2=6.7503, p=$ $0.034)$. There was a significant association $(\mathrm{OR}=$ $2.745, \mathrm{x} 2=11.1048, \mathrm{p}=0.0010)$ between performing particular exercise $(41 \%)$ and non-performing $(59 \%)$; and knee injuries. Most injuries were characteristically mild (58.6\%). Majority of injuries occurred in contact $(74.1 \%)$, during games $(44 \%)$. The significant relationship found between warm up and knee injury $(\mathrm{OR}=2.110, \mathrm{x} 2=5.8808, \mathrm{p}=0.0107)$. Physiotherapy treatment $39.6 \%$ was the second choice of managements. Our findings revealed that midfielders suffered a greater percentage of knee injuries compared to other positions, with injuries being more predominant during match play.
\end{abstract}

Keywords. Football player, knee injury, ligament, male, professional.

\section{Introduction}

On Earth, football is one of the most popular and widespread sports (Arliani, 2011; Tumilty, 1993). With a projection from 240 million in 2000 to 265 million in 2006 players out of in total of 270 million persons participating in the game [FIFA, 2003; FIFA, 2006). Football is among the sports with the highest injury rate (Hootman et al., 2007). Injury sustained by a professional football player is a deep-rooted concern with an estimated of 3.7 million sports injuries in the Netherlands per year, with 42,262 soccer injuries reported in 2003 in Switzerland (Consumer Safety Institute, 2011; Junge, et al. 2011).

In Holland, with the greatest proportion of 620000 injuries happening in outdoor soccer (Consumer Safety Institute, 2011). During the competition, knee injuries account for between $15 \%$ - 58\% of all major injuries (Arnanson et al., 1996; Luthje et al., 1996). Throughout their career, professional footballers are at risk of suffering from severe knee injuries, for instance, an overall Anterior Cruciate Ligament (ACL) injury rate of 0.066 per $1000 \mathrm{~h}$ identified, in the match ACL injury rate is 20 times higher than the training injury rate (Walden, 2016). A cohort study found that a typical squad consisting of 25 players can expect between

Received: February 22, 2019 - Accepted: May 01, 2019 - Published: June 20, 2019

To cite this article: Khan AR, Khan MR, Hawlader MDH. The epidemiological profile of knee injury pattern among different divisional football players. Turk J Kinesiol, 2019; 5(2): 50-56. 
4 and 8 severe knee injuries every season (Gouttebarge, 2016).

Since the knee is biomechanically predisposed to injury, especially during collisions, soccer players are at a greater risk of injury (Lees \& Nolan, 1998; Soligard, 2008), as it is the canter of the level of the leg, and sustains greater forces (Wong \& Hong, 2005). Roughly estimated financial loss due to injuries in professional English football leagues is $€ 118$ million and $€ 95$ million in Switzerland (Woods, 2002, Junge et al., 2011).

The present study carried to understanding the descriptive epidemiology of increased knee injuries sustained by the professional footballers at the aim of providing physiotherapist, athletic trainer, and coach with the evidence required to make effective injury preventive measures.

\section{Methods}

\section{Participants and Design of the Study}

The study representative comprised of male football athletes belongs to five different sports clubs in Dhaka city. A prospective descriptive cross-sectional study conducted on adopted players ranging in age from 14 to 40 years, participating in the first, second and third division matches. The study was conducted over twelve months (March 2011 to February 2012).

Permission granted from the Ethical Committee of State College of Health Sciences (SCHS), Dhaka, Bangladesh. All ethical issues related to research involving human subjects address according to the guidance of the Bangladesh Medical Research Council.

\section{Participants' Selection}

The recruited eligible participants participated for the face to face interview purposively considering the inclusion criteria that who was playing at least 12 months as a professional player. Every participant has the right to refuse and withdraw from the study accepted. All questioner and ethical documents translated into Bengali. Anthropometric measurements obtained from each player included height and weight through the standard instrument and checked each day before taking a measurements of subjects.

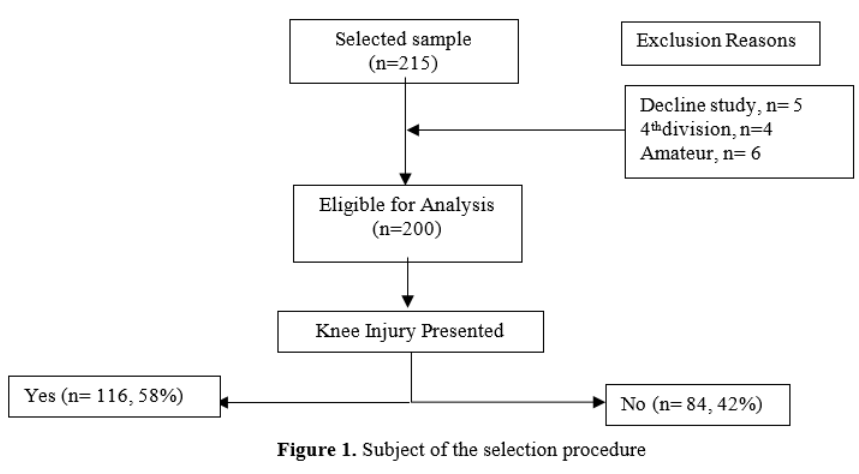

\section{Data Collection}

It involved one constant process to maintain reliability by pre-tested self-made questionnaire, all 200 out of 215 adopted, questionnaire designed to collect information in related to knee injury sportsman that prepared in advance and evaluated by one of the team members of the research group. Data on the type and site of the injury confirmed by the researcher himself from the injured players.

Visual Analog Scale (VAS): It demonstrates positive relations to other self-report measures of pain intensity. Pain measured by four-point pain index a categorical scale where $0=$ no pain, $1=$ mild pain, $2=$ moderate pain and $3=$ severe pain (Jensen et al., 1986).

Psychometric Scale: Likert-type scales are often used in medical education and medical education research (Sullivan \& Artino, 2013). Researcher produces four points Likert questionnaire.

\section{Questionnaire}

A brief self-made questionnaire was administered to all participating players during the regular football season. Prior to the collection of data, the study was explained to each participant in an understandable language. All participants subjected to a structured interview, consisting of baseline characteristics, physical activities, injury related information, treatment-seeking behavior, and psychological condition outcome measurements. 


\section{Statistical Analysis}

Excluding missing and inconsistent data, the data were reported as mean, and frequency tables, chisquare test and $\mathrm{p}$-value presented to find the significant association in between dependent (knee injury) and independent variables. Odds ratios (ORs) and $95 \%$ confidence intervals $(95 \% \mathrm{CI})$ test were computed for determining to compare the risk of a knee injury with other factors.

\section{Results}

The main findings investigating the reasons for and occurrence of knee injury are presented in the tables 1.
In order to assess the anthropometric variables, the mean age of the respondents twenty-seven years at the time of the study. In general, the age of the athletes significantly associated with the knee injuries $\left(x^{2}=7.6013, p=0.0223\right)$. At presentation, normal BMI found $85 \%$ cases and mean the experience of the sporting was eight years where more than half $51 \%$ sporting around $6-10$ years. Athletes considering baseline characteristics, among all presentation, the player position treated as 4 different levels, categorical variable: the goalkeeper position (12\%), striker (29\%), midfielder (35.5\%) and defender (23.5\%) positions, it indicated the significant association of injuries in the knee $\left(x^{2}=10.8214, p=0.013\right)$.

Table 1

Anthropometric measurement and baseline characteristics ( $\mathrm{n}=200)$

\begin{tabular}{|c|c|c|c|c|c|c|}
\hline \multirow{2}{*}{ Variable } & \multirow{2}{*}{ Characteristics } & \multirow{2}{*}{$\mathrm{n}(\%)$} & \multicolumn{2}{|c|}{ Knee injury } & \multirow{2}{*}{$x^{2}$} & \multirow{2}{*}{$\mathrm{p}$} \\
\hline & & & Yes & No & & \\
\hline \multirow[t]{3}{*}{ Age (years) } & $14-22$ & $101(50.5)$ & 47 & 54 & 7.6013 & $0.022^{*}$ \\
\hline & $23-31$ & $83(41.5)$ & 49 & 24 & & \\
\hline & $32-40$ & $16(8)$ & 10 & 6 & & \\
\hline \multirow[t]{3}{*}{ BMI } & $<18.5$ & $10(5)$ & & & & \\
\hline & $18.5-24.9$ & $170(85)$ & & & & \\
\hline & 25- 29.9 & $20(10)$ & & & & \\
\hline \multirow[t]{3}{*}{ Playing experience } & $1-5$ years & $86(43)$ & & & & \\
\hline & 6-10 Years & $102(51)$ & & & & \\
\hline & 11-15 Years & $12(6)$ & & & & \\
\hline \multirow[t]{3}{*}{ Level of competition } & First division & $45(22.5)$ & & & & \\
\hline & Second division & $72(36)$ & & & & \\
\hline & Third division & $83(41.5)$ & & & & \\
\hline \multirow[t]{4}{*}{ Playing position } & Goalkeeper & $24(12)$ & 8 & 16 & 10.8214 & $0.012^{*}$ \\
\hline & Sticker & $58(29)$ & 32 & 26 & & \\
\hline & Midfielder & $71(35.5)$ & 50 & 21 & & \\
\hline & Defender & $47(23.5)$ & 26 & 21 & & \\
\hline \multirow[t]{3}{*}{ Ground condition } & Ups and down & $71(35.5)$ & 40 & 39 & 6.7503 & $0.034^{*}$ \\
\hline & Smooth & $49(24.5)$ & 36 & 13 & & \\
\hline & Rough & $72(36)$ & 40 & 32 & & \\
\hline \multirow[t]{3}{*}{ Nutrition status } & Very good & $60(30)$ & 32 & 28 & 52.4547 & $0.000^{*}$ \\
\hline & Good & $128(64)$ & 79 & 49 & & \\
\hline & Poor & $12(6)$ & 5 & 60 & & \\
\hline
\end{tabular}


Table 2

Information related to routine physical activities $(\mathrm{n}=200)$.

\begin{tabular}{|c|c|c|c|c|c|c|c|c|}
\hline \multirow[t]{2}{*}{ Variables } & \multirow{2}{*}{ Characteristics } & \multirow{2}{*}{ n $(\%)$} & \multicolumn{2}{|c|}{ Knee injury } & \multirow{2}{*}{ OR } & \multirow{2}{*}{$95 \% \mathrm{CI}$} & \multirow{2}{*}{$x^{2}$} & \multirow{2}{*}{$\mathrm{p}$} \\
\hline & & & Yes & No & & & & \\
\hline \multirow[t]{2}{*}{ Fitness training } & Yes & $113(56.5)$ & 62 & 51 & \multirow[t]{2}{*}{0.742} & \multirow{2}{*}{$\begin{array}{c}0.4202- \\
1.3136\end{array}$} & \multirow[t]{2}{*}{1.0466} & \multirow[t]{2}{*}{0.306} \\
\hline & No & 87 (43.5) & 54 & 33 & & & & \\
\hline \multirow[t]{2}{*}{ Vigorous exercise ( knee joint) } & Yes & $82(41)$ & 59 & 23 & \multirow[t]{2}{*}{2.745} & \multirow{2}{*}{$\begin{array}{c}1.5035- \\
5.0126\end{array}$} & \multirow[t]{2}{*}{11.1048} & \multirow[t]{2}{*}{$0.001^{*}$} \\
\hline & No & $118(59)$ & 57 & 61 & & & & \\
\hline \multirow[t]{2}{*}{ Warm up } & Yes & $114(57)$ & 75 & 39 & \multirow[t]{2}{*}{2.110} & \multirow{2}{*}{$\begin{array}{l}1.1896- \\
3.7450\end{array}$} & \multirow[t]{2}{*}{5.8808} & \multirow[t]{2}{*}{$0.010^{*}$} \\
\hline & No & $86(43)$ & 41 & 45 & & & & \\
\hline \multirow[t]{2}{*}{ Practice football } & Yes & $90(45)$ & & & & & & \\
\hline & No & $110(55)$ & & & & & & \\
\hline
\end{tabular}

${ }^{*} \mathrm{p}<.05$

Table 3

Information related to knee injury $(n=200)$ except no injury $(n=84)$.

\begin{tabular}{llc}
\hline Variables & Characteristics & $\mathrm{n}(\%)$ \\
\hline Type of injury & Contact & $86(74.1)$ \\
& Non-contact & $30(25.9)$ \\
Injury time & Recent (1-7 days) & $63(54.3)$ \\
& $>6$ weeks & $53(45.7)$ \\
Injury incidence & Match & $51(44)$ \\
time & Practice match & $39(33.6)$ \\
& Recreational activity & $10(8.6)$ \\
& Others & $16(13.8)$ \\
Event of injury & First time & $72(62)$ \\
& Repeated & $44(38)$ \\
Injury nature & Ligament & $74(63.8)$ \\
& Tendon & $25(21.6)$ \\
& Meniscus & $10(8.6)$ \\
& Contusion & $7(6)$ \\
Severity of injury & Mild & $68(58.6)$ \\
& Moderate & $32(27.6)$ \\
& Severe & $16(13.8)$ \\
\hline
\end{tabular}

Almost equal cases reported whether they played in the ground with ups and down $35.5 \%(n=71)$ or rough field $36 \%(n=72)$. The ground condition reflects their greater injurious condition (40 injured athletes) $\left(x^{2}=6.7503, p=0.034\right)$. It was also reflecting in nutritional status of the sportsman around more than $90 \%$ nutritional status was perfect; $30 \%$ very good and $64 \% \quad(n=128)$ good and higher relationship causing knee injuries $\left(x^{2}=52.4547, p\right.$ $=0.00001$; Table 1 ).

Regarding exercise activities, 56.5\% $(n=113)$ respondents attended regularly predesigned training session for uplifting their physical fitness and fitness training clearly designate the nonsignificant difference $\left(\mathrm{OR}=0.742, \mathrm{x}^{2}=1.0466, \mathrm{p}=\right.$ 0.306). Athletes involved with the regular vigorous exercise, the significant difference $\left(x^{2}=11.1048, p=\right.$ 0.0010 ) also observed higher relationship ( $\mathrm{OR}=$ $2.745,95 \% \mathrm{CI}=1.5035$ - 5.0126) due to the adequate exercises, proper conditioning, and certified trainer. As shown in table 1, warm up and knee injury, indicating there were significant differences and association $(\mathrm{OR}=2.110,95 \% \mathrm{CI}=1.1896-3.7450$ and $\left.\mathrm{x}^{2}=5.8808, \mathrm{p}=0.0107\right)$.

\section{Table 4}

Treatment-seeking behavior and psychometric factor $(n=116)$ except no injury ( $\mathrm{n}=84)$.

\begin{tabular}{llc}
\hline Variables & Characteristics & $\mathrm{n}(\%)$ \\
\hline Treatment after injury & Yes & $105(90.5)$ \\
& No & $11(9.5)$ \\
Management & Medical & $55(47.4)$ \\
& Physiotherapy & $46(39.6)$ \\
& Others & $15(13)$ \\
Surgery & Yes & $2(1.7)$ \\
Playing stress & No & $114(98.3)$ \\
& Yes & $118(59)$ \\
Satisfaction of coaching & No & $82(41)$ \\
& Yes & $142(71)$ \\
Level of satisfaction & No & $58(29)$ \\
& Satisfied & $62(31)$ \\
& Highly Satisfied & $81(40.5)$ \\
& Not Satisfied & $34(17)$ \\
& Poor & $23(11.5)$ \\
\hline
\end{tabular}


Contact injury accounted for mostly $74.1 \%$ $(n=86)$, in the history of injury time, the recent injury listed by highest $54.3 \%(n=63)$ and more event occurred in the first time considerably higher as of $62 \%(\mathrm{n}=72)$. The nature of the injuries consisted of $63.8 \%(n=74)$ ligaments injury, $21.6 \%$ $(\mathrm{n}=25)$ tendons, and $8.6 \%(\mathrm{n}=10)$ to the meniscus. Major $58.6 \%(n=68)$ contributors described they had a mild injury and $13.8 \%(n=16)$ defined injury was more severe (Table 3 ).

The overall treatment receiving rate after a knee injury was $90.5 \%$, for the choice of management, underwent directly to the physiotherapy 39.6\% which less than that for those who went to physician $47.4 \%$. Of all footballers with a knee injury, only $1 \%$ required knee surgery but the rest, major $58 \%$ continued to play with the use of a conservative approach combining medicine and physiotherapy. All athletes with state of satisfaction, more than half of played under stress $59 \%(n=118)$ and the majority of $71 \%(n=142)$ of the study participants satisfied with coaching, and very pleased were around $40.5 \%$ (Table 4 ).

\section{Discussion}

In this study, we observed that $58 \%$ of the participants suffered some form of knee injury. Opposite to our study where $28.13 \%$ knee injuries recorded among athletics (Wekesa, 1995) and a study with a large sample size, almost similar findings quoted in the lower limbs; the knee 29.9\% (Herrero et al., 2013) but much higher $44.44 \%$ of the ligaments injuries affected the knee out of 45 ligaments injuries, which support our study (Arnason, 2007; Figure 1).

The mean age of the respondents in our study twenty-seven years at the time of the study and maximum knee injuries observed in the age range of 23 to 31 years, statistically significant $\left(x^{2}=7.6013\right.$, $p=0.0223$ ). Much lower mean age, the footballers estimated at 19.33 (Kumar et al., 2008). The earlier researchers studied the relation of soccer injuries to age, where they found the higher rates of injury occur in the age range from 16 to 18 years (Watson, 1986). In our study, major $35.5 \%(n=50)$ were playing at the position midfielder and lowest $12 \%$ $(\mathrm{n}=8)$ goalkeeper found significant relationship with injuries $\left(x^{2}=10.8214, p=0.012\right)$. Similar to our study, a $25 \%$ injury rate was reported amongst center half or midfielders, with goalkeepers being $13.88 \%$ (Nader et al., 2009). Knee injuries were responsible for the ground condition in male professional sportsperson significantly associated $\left(x^{2}=6.7503, p=0.034\right)$. In a study determined that $10 \%$ of cases ground causes a reason for the injury (Wekesa, 1995; Table 1).

Research work explored that the frequency of contact injuries was lower than non-contact injuries (Roi, 2005). With the support of the previous study, around $35 \%$ and $65 \%$ were contacted injury and noncontact injury respectively. In this study, where contact injury largest $74.1 \%$ and noncontact injury least $25.9 \%$. In favor of our findings, the percentage of injuries resulting from player-toplayer contact varied from $31-70.3 \%$ with regard to indoor compared to $43-60.9 \%$ for outdoor soccer (Albert, 1983). It is interesting to note that a higher percentage of injuries occurred in female sports due to contact, $62.3 \%$ (Jacobson, 2007). This study investigated the injury time; the recent injury noted by $54.3 \%$ where in the case of $45.7 \%$ injury took place $>6$ weeks. The study exposed the similar higher trend of a recent injury that, major 39\% injuries recognized within 7 days and 23\% lasted more than 3 weeks (Arnason, 2007). Most injuries around $44 \%$ occurred during a match where there was a higher risk of injury compared with training; $33.6 \%$ in practice, and $8.6 \%$ in recreational activities. Almost similar result found in another study within female athletic, the more injuries $46.1 \%$ documented during matches than training session $36.8 \%$ (Jacobson, (2007). The study also described the reverse findings that $57.40 \%$ of injuries arise during training while $42.59 \%$ occurred during competition (Nader et al., 2009). Considering the category of injury nature, cases of contusion amount to merely $6 \%$ compared to ligament which was $63.8 \%$. In contrast, a recent study indicated contusion common types of injuries, with a high incidence in soccer players $23.5 \%$, while muscle and tendon damage presented in $17.4 \%$ of the injuries (Herrero et al., 2013). The mild injury as $58.6 \%$ was the highest form of 
severity and $13.8 \%$ described injury was more severe. Opposite to our study findings, lowest $16.7 \%$ were mild injuries, and the highest remaining $47.4 \%$ were severe injuries (Herrero et al., 2013). Another study on male and female, injury incidence in élite football players mild were slightly higher $29 \%(n=158)$, and severe $9 \%(n=48)$ (Hagglund et al., 2009; Table 3).

Most of the researchers observed that a lower number of athletes consulted by the physiotherapists than physicians (Kumar et al., 2008). Compared the treatment management where physician managed $47.4 \%$ and athletes treated by physiotherapist $39.6 \%$ in this study. Other researcher detected that $46.83 \%$ of athletes got their injuries treated by a physician and footballers who went to physiotherapists $29.11 \%$ for treatment (Kumar et al., 2008; Table 4).

\section{Conclusion}

The high number of knee injuries among Bangladeshi professional soccer is alarming. The higher percent of knee injuries challenges physiotherapists and sports medicine professionals to identify the injury patterns and causes such as age, ground condition, player to player high-speed collisions, particular exercise, and psychological factors like stress management.

\section{Recommendation}

The results of the present study could be helpful in preventing knee injury by designing a particular exercise regime and improve the playground condition.

\section{References}

Albert, M. Descriptive three years data study of outdoor and indoor soccer injuries. Athletic Training, 1983; 18: 218-20.

Arliani, GG, Belangero PS, Runco JL, Cohen M. The Brazilian Football Association (CBF) model for epidemiological studies on professional soccer player injuries. Clinics, 2011; 66(10): 1707-12.

Arnanson A, Gudmundsson A, Dahl HA. Soccer injuries in Iceland. Scand J Med Sci Sport, 1996; 6: 40-45.
Arnason A, Sigurdsson SB, Gudmundsson A, Holme I, Engebretsen L, Bahr R. Risk factors for injuries in football. Am J Sports Med, 2004; 32(1Suppl): 5S-16S.

Consumer Safety Institute. Factsheet on sports injuries [Dutch]. Consumer Safety Institute, Amsterdam, 2011.

FIFA. 2003. https://www.fifa.com/news/ $y=2003 / \mathrm{m}=4 /$ news $=$ how-many-people-play-football-worldwide-86821.html (cited 2018, 29 July).

FIFA. 2006. Fédération Internationale de Football Association. FIFA Big Count 2006: 270 million people active in football. (2007). [cited 2012, July 10]. Available from: http://www.fifa.com/mm/document/fifafacts/bcoffsurv/bi gcount.statspackage_7024.pdf3.

Gouttebarge V, Schwab BAH, Vivian A, Kerkhoffs G. Injuries, matches missed and the influence of minimum medical standards in the a-league professional football: A 5-year prospective study. Asian J Sports Med, 2016; 7: e31385.

Hagglund M, Walde' n M, Ekstrand J. Injuries among male and female elite football players. Scand J Med Sci Sports, 2009; 19: 819-827. doi: 10.1111/j.1600-0838. 00861.x

Herrero H, Salinero JJ, Coso JD. Injuries among Spanish male amateur soccer players a retrospective population study. The American Journal of Sports Medicine, 2013; 42(1): 7885. doi: $10.1177 / 0363546513507767$.

Hootman JM, Dick R, Agel J. Epidemiology of collegiate injuries for 15 sports: summary and recommendations for injury prevention initiatives. J Athl Train, 2007; 42(2): 3119.

Jacobson I. Injuries among female football players. Doctoral Thesis, Luleå University of Technology, 2006.

Kumar SS, Jadhav KG, Pagare S. A pilot study examining injuries in relation to field position of competitive football players. J Physiother Phys Rehabil, 2008; 4(1): 50-54.

Jensen MP, Karoly P, and Braver S. The measurement of clinical pain intensity: a comparison of six methods. Pain, 1986; 27(1): 117-26.

Junge A, Lamprecht $M$, Stamm $H$, Hasler $H$, Bizzini $M$, Tschopp M, Reuter H, Wyss H, Chilvers C, Dvorak J. Countrywide campaign to prevent soccer injuries in Swiss amateur players. Am J Sports Med, 2011; 39: 57-63.

Lees A, Nolan L. The biomechanics of football: A review. J Sports Sci, 1998; 16(3): 211-234.

Luthje P, Nurmi I, Kataja M. Epidemiology and traumatology of injuries in elite soccer: a prospective study in Finland. Scan J Sci Sports, 1996; 6(3): 180-185.

Nader R, Effat B, Abdol HD. The epidemiology of knee injuries in Iranian male professional soccer Players. J Sport Sci Health, 2009; 5: 9-14. doi: 10.1007/s11332-009-0070-1.

Roi GS, Nanni G, Tavana R, Tencone F. Prevalence of anterior cruciate ligament reconstructions in professional soccer 
players. Sport Sci Health, 2006; 1(3): 118-121. DOI 10.1007/s11332-006-0021-z

Soligard T, Myklebust G, Steffen K, Holme I, Silvers H, Bizzini M, Junge A, Dvorak J, Bahr R. Comprehensive warm-up programme to prevent injuries in young female footballers: cluster randomised controlled trial. BMJ, 2008; 337: a2469.

Sullivan GM, Artino JrA R. Analyzing and interpreting data from likert-type scale. J Grad Med Educ, 2013; 5(4): 541542. doi: 10.4300/JGME-5-4-18

Tumilty D. Physiological characteristics of elite soccer players. Sports Med, 1993; 16(2): 80-96. doi: 10.2165/00007256199316020-00002

Walden M, Hagglund M, Magnusson H, Ekstrand J. ACL injuries in men's professional football: a 15-year prospective study on time trends and returnto-play rates reveals only $65 \%$ of players still play at the top level 3 years after ACL rupture. Br J Sports Med, 2016; 50: 44-50.

Wekesa M. A one-year prospective study of Soccer injuries in the 1992-1993 Kenyan National Team. Afr J Health Science, 1995; 2(4): 392-394.

Wong $\mathrm{P}$, Hong Y. Soccer injury in the lower extremities. Br J Sports Med, 2005; 39(8): 473-482.

Woods C, Hawkins R, Hulse M, Hodson A. The Football Association Medical Research Programme: an audit of injuries in professional football-analysis of preseason injuries. Br Sports Med, 2002; 36(6): 436-441.

Watson AWS. Sports injuries in Irish second hand schools during the school year 1984-1985. Dublin, Department of Education, 1986. 